\title{
Relationship between Attachment Style and Alexithymia With Marital Dissatisfaction
}

\author{
Tayebe Khosravi ${ }^{1,}$; Shahrbanoo Ghahari ${ }^{1}$; Fateme Ahadi ${ }^{2}$ \\ ${ }^{1}$ Department of Clinical Psychology, Azad Islamic Universiry, Tonekabon Branch, Tonekabon, IR Iran \\ ${ }^{2}$ Nursing and Allied Health Sciences, School of Medicine, Department of Pediatrics, Semnan University, Semnan, IR Iran \\ ${ }^{*}$ Corresponding author: Tayebe Khosravi, Department of Clinical Psychology, Azad Islamic Universiry, Tonekabon Branch, Tonekabon, IR Iran. Tel: +98-9376298422, E-mail:khosravi.tara@gmail.com
}

Received: May 24, 2015; Revised: July 27, 2015; Accepted: July 29, 2015

\begin{abstract}
Background: Marital quality is deeply associated with its psychological, physical, and emotional aspects.
Objectives: The current study aimed to investigate the relationship between marital dissatisfaction and variables of attachment styles and alexithymia.

Patients and Methods: This research method is descriptive and correlational. The population study comprised 400 parents of female students in Tehran during the academic year of 2013 -2014. The study sample was selected using multistage cluster sampling method. The Pearson correlational coefficient and multivariate regression methods have been used for data analysis. Statistical analysis was done by SPSS 18.

Results: The results showed a significant negative correlation between secure style and marital satisfaction $(P=0.001, r=-0.154)$. Also, significant relationships were observed between marital dissatisfaction and variables of insecure style $(\mathrm{P}=0.001, \mathrm{r}=0.243)$, ambivalent style $(\mathrm{P}=0.001, \mathrm{r}=0.247)$, difficulty in emotional identification $(\mathrm{P}=0.001, \mathrm{r}=0.335)$, and external orientation $(\mathrm{P}=0.001, \mathrm{r}=0.286)$. However, there was no significant relationship between marital dissatisfaction and difficulty in describing emotions $(\mathrm{P}=0.001, \mathrm{r}=0.033)$.

Conclusions: The results have shown a significant negative correlation between secure style and marital dissatisfaction. There were positive significant relationships between marital dissatisfaction and variables of insecure style, ambivalent style, difficulty in identifying emotions, and externally oriented thinking, but there was not any significant relationship between marital dissatisfaction and difficulty in emotional expression.
\end{abstract}

Keywords: Alexithymia; Attachment; Alexithymia; Marriage

\section{Background}

The overall assessment of the couple's marital satisfaction and meeting their needs and demands (1) have a deep association with their psychological, emotional, and physical aspects (2). Marital dissatisfaction is developed through negative feedbacks from couples' conflicts and ignorance of partner's emotions (3). Attachment is a specific behavioral pattern that is crucial for the development of a healthy personality. Secure attachment occurs when a mutual and pleasurable state develops between the couple. This warm, sincere and lasting relation is satisfactory for both partners (4). Hazan and Shaver studied the nature of intimate bonding and the role of mental attachments among adults. The results showed that the characteristics of the bond with emotional ties between couples are comparable to the characteristic of the child-mother bonding. Known attachment styles includes secure, insecure, and ambivalent that affect couples' thoughts, feelings, and behaviors in marital relationships (5). Hazan and Shaver stated that attachment styles reflect the fundamental differences in mental imagery representing romantic love.

Securely attached people describe their love experiences as joyful, reliable, supportive, and pleasant. On the other hand, insecurely attached individuals describe their love experiences with a fear of intimacy. People with ambivalent style describe their experiences as obsessive with extreme jealousy and intense sexual attraction. These researchers have shown positive correlation between attachment styles and marital satisfaction, and a negative correlation between insecure attachment and marital satisfaction $(6,7)$. The research on attachment shows that insecure attachment is highly related with alexithymia (8, 9). Feeling insecure in attachment relationships predicts defects and failure in identifying and expressing emotions (8). Based on other research in this field (10-12), subjects with secure attachment style have less interpersonal and marital problems in comparison to subjects with insecure and ambivalent attachment styles.

Therefore, people with secure style by expressing intimacy and emotions about love and friendship, create a situation, which leads them to feel more satisfied. While those with insecure and ambivalent styles report the quality of marital relationship as negative, emotionally distancing, and anxious (13). One of the variables studied in relation to the human emotion is alexithymia that has a direct effect

Copyright (C) 2015, Semnan University of Medical Sciences. This is an open-access article distributed under the terms of the Creative Commons Attribution-NonCommercial 4.0 International License (http://creativecommons.org/licenses/by-nc/4.0/) which permits copy and redistribute the material just in noncommercial usages, provided the original work is properly cited. 
on mental functioning. When people have the emotional capacity, they can meet the challenges of life while improving their mental health and life satisfaction. People who are weak in identifying and using emotions may lack the ability to take advantage of their emotional world; therefore, they fail to experience positive emotions such as happiness which are low in these people (14).

Effective communication has a prominent role on marital satisfaction (15) and could have an important role in creating security for couples (16). Emotional expression is a fundamental factor in the differentiation between unhappy and happy couples, because it plays an important role in the development of intimacy in a relationship (17, 18). Mutual expression of affection creates a sense of support and increases self-revelation in couples (19). The study results showed that self-revelation behavior of couples has a positive correlation with marital satisfaction (20). Also, emotional skills and the ability to express emotion have a positive correlation with marital satisfaction (21). The study results confirm the relationship between alexithymia and avoidance of intimacy (22), suggesting that people with alexithymia, have a strong need for independence, which results from their doubt and mistrust in others (23). On the other hand, people's mental and physical well-being are significantly influenced by their close relationship. Ability to establish and maintain a satisfying romantic relationship requires the ability to identify emotions and feelings and express them $(24,25)$, as well as the ability to understand and appreciate the feelings of others (26). Results showed that alexithymia has a positive relationship with difficulty in communicating and getting close to others, and the need for being approved by others. However, it has a negative relationship with trusting others (the characteristics of insecure individuals) (27).

Evaluating factors associated with marital dissatisfaction seems necessary because the role of marital satisfaction is important in mental health, physical health, efficiency, productivity, and social contributions of the spouses. Couples, who perceive marital dissatisfaction, undergo a lot of stress and suffering.

\section{Objectives}

The present study aimed to investigate the relationship between marital dissatisfaction and attachment styles as well as alexithymia. Also in this study, the association of marital dissatisfaction with variables of secure style, insecure style, ambivalent style, as well as difficulty in identifying feelings, externally oriented thinking, external orientation, and difficulty in describing feelings has been examined.

\section{Patients and Materials}

Research population included the parents of female elementary students (due to limited access to the parents of male students) in Tehran during the academic year of 2013 - 2014. The study sample was recruited using a multi- stage cluster sampling method. To determine the sample size based on Morgan's table (1974), in a study population of 400 , a number of 196 samples were obtained. For enhancing the quality of the research, 250 participants were enrolled for this study; with the loss of 50 people, the sample reduced to 200 . Inclusion criteria included having at least an associate degree and exclusion criterion was being a single parent. The study method was descriptive. A list of elementary school girls was provided from the Tehran municipality district 2 . Then, 3 girls' schools were randomly selected, and in the next step, 3 different classes were selected. Next, based on the parents' population of each class, the couples were randomly selected. After selecting the sample from statistical population, the questionnaires were distributed among the parents of the students and after answering, they were collected. For analyzing the assumptions of this study, the Pearson correlational coefficient and multivariate regression methods were used. Also, SPSS 18 software has been used for the conversion and analysis of the scores.

To measure marital satisfaction in this study, ENRICH marital satisfaction questionnaire was used. This questionnaire was designed by Olson (1989), and used for evaluating potential areas of conflict and identifying areas of strength and fulfillment of marital satisfaction. This test has two forms, one with 115 questions and the other with 125 that consists of 12 subscales. The original form was tiring for the subjects because of its too many questions; therefore, we provided a shorter version of this questionnaire with 47 questions. In the original marital satisfaction form of ENRICH, the validity was reported 0.90 using the Cronbach $\alpha$ coefficient (28). Likewise, the validity of the shorter version was 0.90 by calculating the Cronbach $\alpha$ coefficient. In the current study, the short version of the questionnaire has been used. A lot of research on the validity and reliability of this test were done and were reported the levels of validity between 0.65 and 0.94 in the test-retests, and its discriminating power as 0.90 (29).

Attachment styles questionnaire is a 15-question test evaluating 3 styles of attachment, including secure, avoidant, and ambivalent in a range of 1 to 5 point Likertscale from very low, 1 ; low, 2; medium, 3; high, 4 ; and very high, 5, and each subscale has 5 questions (29). Validity of the questionnaire has been studied by evaluating the correlation between the scores of the 15 psychological professionals. Kendall coefficients of agreement for secure attachment style, avoidant, and ambivalent were $0.80,0.61$, and 0.57 , respectively. Reliability coefficients were obtained using Cronbach $\alpha$ as $0.86,0.87$ and 0.88 for secure attachment style, avoidant, and ambivalent, respectively (29).

In the questionnaire, the alexithymia indicator of Toronto 20 is evaluated by 3 subscales of difficulty in identifying feelings, difficulty describing feelings, and externally oriented thinking. The first subscale includes 7 items ( 1 , $3,6,7,9,13,14)$, which evaluates the participants' ability in distinguishing and identifying feelings and emotions 
from their physical senses. Second subscale has 5 items $(2,4,11,12,17)$, which evaluates the ability to determine the expression of emotions and whether the participant can express feelings using words. The third subscale has 8 items $(5,8,10,15,16,18-20)$ which evaluates the levels of one's introspection, depending in one's own feelings and also in others. Test scoring method is based on a Likertscale from 1 (strongly disagree) to 5 (strongly agree). The only items with invert scores are $4,10,18$, and 19 . The reliability of this scale was calculated as 0.87 using the Cronbach $\alpha$ for the total scale. The calculated reliability for the total scale and 3 components of difficulty in identifying feelings, difficulty in describing feelings, and externally oriented thinking (thinking with external orientation) were $0.88,0.82,0.80$, and 0.70 , respectively using the Cronbach $\alpha$. Also, retest reliability was found from 0.87 to 0.80 using a sample of 67 students in two tests with a 4-week interval (30).

\section{Results}

The results of the correlation coefficient between the predictor variables and marital dissatisfaction are shown in Table 1. Other than the difficulty in describing feelings variable, there is a significant correlation between all predictor variables and marital dissatisfaction.

Results of stepwise regression analysis of predictive variables and marital dissatisfaction are shown in Table 2.
Step 1, the score of ambivalent style inserted in the model and this variable was able to explain $6 \%$ of variance $\left(\mathrm{R}^{2}\right.$ $=0.061$ ). Addition of secure style into model 1 in the second step caused another $6 \%$ addition to the variance $\left(\mathrm{R}^{2}=\right.$ $0.120)$. Addition of insecure style variable to the first two variables in the third step, added about $2 \%$ to the variance $\left(R^{2}=143\right)$. In the fourth step, externally oriented thinking variable was added to the previous variables that explained about $7 \%$ of the variance $\left(R^{2}=0.230\right)$. In the fifth step, the difficulty in identifying feelings variable was added to the previous ones that explained about $2 \%$ of the variance $\left(R^{2}=0.252\right)$.

The results from the variance analyses of 5 model regression are shown in Table 3. It shows that there are relationships between marital dissatisfaction and variables of ambivalent style, secure style, insecure style, externally oriented thinking, and difficulty in identifying emotions. The results of the bivariate and partial correlations of predictors with marital dissatisfaction are shown in the Table 4. There is a significant relationship between predictive variables and marital dissatisfaction in all bivariate correlations of marital dissatisfaction. There is also a significant relationship between all other indicators and marital dissatisfaction except for insecure style. Thus, among the predictive variable, difficulty in identifying emotion and secure style predict the changes in marital dissatisfaction.

Table 1. The Matrix of Correlation Coefficients of the Predictor Variables and Marital Satisfaction

\begin{tabular}{lcc}
\hline Predictor Variables & R & PValue \\
\hline Secure style & $-0.154^{\mathrm{a}}$ & 0.001 \\
\hline Insecure style & $0.243^{\mathrm{a}}$ & 0.001 \\
\hline Ambivalent style & $0.247^{\mathrm{a}}$ & 0.001 \\
Difficulty in identifying feelings & $0.355^{\mathrm{a}}$ & 0.001 \\
\hline Difficulty describing feelings & $0.033^{\mathrm{a}}$ & 0.255 \\
\hline Externally oriented thinking & $0.286^{\mathrm{a}}$ & 0.001 \\
\hline
\end{tabular}

a $\mathrm{P}<0.01$

Table 2. Summary of the Stepwise Regression Analysis of Predictive Variables and Marital Satisfaction

\begin{tabular}{|c|c|c|c|c|c|}
\hline Step & Predictive Component & $\mathbf{R}$ & $\mathbf{R}^{2}$ & Discounted $\mathbf{r}$ & Standard Error \\
\hline $\mathbf{1}$ & Ambivalent style & 0.247 & 0.061 & 0.059 & 22.121 \\
\hline 2 & Secure style & 0.347 & 0.120 & 0.116 & 21.443 \\
\hline 3 & Insecure style & 0.379 & 0.143 & 0.137 & 21.186 \\
\hline 4 & Externally oriented thinking & 0.480 & 0.230 & 0.220 & 20.136 \\
\hline 5 & Difficulty in identifying feelings & 0.502 & 0.252 & 0.241 & 19.866 \\
\hline
\end{tabular}


Khosravi Tet al.

\begin{tabular}{|c|c|c|c|c|c|}
\hline Source of Change & Sum of Squares & Degree of Freedom & Mean of Squares & $\mathbf{F}$ & P Value \\
\hline Model 1 & & & & & 0.000 \\
\hline Regression & 12639.526 & 1 & 12639.526 & 25.828 & \\
\hline Error & 193792.112 & 396 & 489.374 & & \\
\hline Sum & 206431.638 & 397 & & & \\
\hline Model 2 & & & & & 0.000 \\
\hline Regression & 24806.705 & 2 & 12403.352 & 26.975 & \\
\hline Error & 181624.934 & 395 & 459.810 & & \\
\hline Sum & 206431.638 & 397 & & & \\
\hline Model 3 & & & & & 0.000 \\
\hline Regression & 29580.848 & 3 & 9860.283 & 21.967 & \\
\hline Error & 176850.790 & 397 & 448.860 & & \\
\hline Sum & 206431.638 & 397 & & & \\
\hline Model 4 & & & & & 0.000 \\
\hline Regression & 47490.729 & 5 & 9498.146 & 23.426 & \\
\hline Error & 158940.909 & 392 & 405.462 & & \\
\hline Sum & 206431.638 & 397 & & & \\
\hline \multicolumn{6}{|l|}{ Model 5} \\
\hline Regression & 52112.310 & 6 & 8685.385 & 22.006 & 0.000 \\
\hline Error & 154319.328 & 391 & 394.679 & & \\
\hline Sum & 206431.638 & 397 & 12639.526 & & \\
\hline
\end{tabular}

Table 4. Bivariate and Detailed Predictive Correlations With Marital Dissatisfaction

\begin{tabular}{lcc}
\hline Variable & Bivariate Correlation & Partial Variable \\
\hline Ambivalent style & $0.247^{\mathrm{a}}$ & $0.109^{\mathrm{b}}$ \\
Secure style & $-0.154^{\mathrm{a}}$ & $-0.295^{\mathrm{a}}$ \\
Insecure style & $0.243^{\mathrm{a}}$ & 0.099 \\
Externally oriented thinking & $0.286^{\mathrm{a}}$ & $0.172^{\mathrm{a}}$ \\
Difficulty in identifying feelings & $0.355^{\mathrm{a}}$ & $0.171^{\mathrm{a}}$
\end{tabular}

${ }_{\mathrm{a}} \mathrm{P}<0.01$.

$\mathrm{b} \mathrm{P}<0.05$.

\section{Discussion}

Our study results showed a significant negative correlation between marital dissatisfaction and secure attachment style. As secure attachment increases, marital dissatisfaction decreases. This finding is consistent with the findings of previous studies (31-35). However, Richard and Holley's results are not in line with the results of the present study (36). Regarding the first hypothesis of this study, it could be said that in the couples' lives, the existence of 
constructive interactions is based on an intimacy and empathy. Secure style between couples makes life more purposeful for them and they face stressful events with empathy and a sense of belongingness and solidarity.

Based on the findings of the present study, there is a significant positive relationship between marital dissatisfaction and insecure style, meaning that when insecure attachment increases, the marital dissatisfaction increases as well. The findings of this research are consistent with the findings of some previous studies (31-33, 35-37). Regarding the second hypothesis, it could be said that from cognitive point of view, individuals with insecure attachment have an insensitive personality. Insecure attachment in couples causes emotional withdraw, lack of feelings, inability to maintain relationships, poor and immature coping skills, defect in cognitive style, intrapsychic and interpersonal conflict, lack of awareness of the feelings of the spouse. These factors increase marital conflicts, which have negative correlation with happiness and marital adjustment.

According to the findings of the present study, there is a significant correlation between ambivalent style and marital dissatisfaction. In other words, as the ambivalent style of attachment increases, marital dissatisfaction also increases. Results of previous studies $(31-33,35,36)$ confirm the findings of this study. The third hypothesis explains that couples with ambivalent attachment styles in romantic relationships are dependent, and constantly worrying about abundance and rejection by the other; also, by depending deeply on one another, they try to decrease their separation anxiety. These problems are directly correlates with marital satisfaction.

The results of this study showed that there is a significant and positive correlation between the difficulty in identifying feelings and marital dissatisfaction. In other words, when identifying feelings gets difficult, marital dissatisfaction increases. Results of the present study are consistent with the findings of previous studies (38-41). The fourth research hypothesis could explain that difficulty in recognition of emotions results in the lack of explicit expression of emotions, feelings of shame, anger and aggression, inhibition of expression vulnerability, lack of joy and satisfaction, and compliance between the couple which maximizes marital conflicts. Based on Ellis' point, marital satisfaction is a subjective feeling of happiness, satisfaction, and enjoyment experienced by husband or wife (42). According to the results of the present study, there is no significant relationship between marital satisfaction and difficulty in describing feelings. This result is not consistent with the previous study results (39-41). Regarding the hypothesis of this study, it could be said that difficulty in describing feelings is usually seen in individuals who have problems in identifying, processing, and regulating their emotions. These people never had the opportunity to acquire the ability to express and recognize emotions in the family environment. It seems that studied couples had fewer problems with each other in describing emotions.

Based on the results of current study, there is a positive and significant correlation between externally oriented thinking and marital dissatisfaction. This result is consistent with the previous research results (39-41). With regard to the hypothesis, weak levels of cognition, lack of objective expression of emotions, and lack of capacity for imagination result in poor thoughts and evocations experiences; people fail to recognize their feelings and emotions. In general, problems with verbal expression of emotions and impairment in cognitive processes are associated with marital dissatisfaction.

\subsection{Research Limitations}

This study had some limitations as follows: limited access to parents of male students, lack of cooperation of some parents in completing the questionnaires, especially highly educated couples, lack of correct and understandable translations of the tests, which could produce some problems in understanding questions and answering them wrong, and possibility of the access to wives to answer sheets that could have caused dishonesty of participants.

\subsection{Research Suggestions}

For future research, we recommend that the causes and dimensions of cognitive, emotional, social, and other matters related to marital satisfaction be investigated. A comparison of attachment styles, alexithymia, and marital dissatisfaction in terms of gender is also suggested. Based on the results of research, family counseling centers and media should pay attention to the education of attachment styles, alexithymia, and strengthening marital satisfaction to reduce marital dissatisfaction. Family courts and other institutions related to family education should present issues related to marital satisfaction in the form of presentations, conferences, and seminars for couples. Given the large figure of divorce in the country, welfare agencies, family courts, counseling centers, and national media should cooperate for creating marital satisfaction and use consultants in the area of family in a professional manner to describe marital satisfaction aspects to couples and families.

\section{Acknowledgements}

We feel obliged to thank professors of clinical psychology department of Islamic Azad university in Tonekabon, Tehran education officials, principals of the selected schools, dear parents, and all those who helped in the this study and the dear judges who have facilitated the implementation and promotion of this study.

\section{References}

1. Birtchnell J, Gelles RJ. Contemporary families: A sociological view. 
Princess RD, East, Leicester, Leics, England LE1 7DR: St. Andrews House; 1995.

2. Doblin GH. The effect of hope, forgiveness and combined marital counseling on interpersonal cognitive distortions of divorcing couples. Woman Stud. 2010;6(3):97-11.

3. de Sousa A, McDonald S, Rushby J, Li S, Dimoska A, James C. Understanding deficits in empathy after traumatic brain injury: The role of affective responsivity. Cortex. 2011;47(5):526-35.

4. Sharf R. Theories of psychotherapy $\&$ counseling: Concepts and cases. Cengage Learning; 2015.

5. Hazan C, Shaver P. Romantic love conceptualized as an attachment process. J Pers Soc Psychol.1987;52(3):511-24

6. Brennan KA, Shaver PR. Dimensions of Adult Attachment, Affect Regulation, and Romantic Relationship Functioning. Personal Soc Psychol Bull.1995;21(3):267-83.

7. Feeney JA. Attachment, caregiving, and marital satisfaction. Pers Relatsh. 1996;3(4):401-16.

8. Besharat MA. Attachment styles and alexithymia. Psychol Res. 2009;24:63-80.

9. Montebarocci O, Codispoti M, Baldaro B, Rossi N. Adult attachment style and alexithymia. Personality and Individual Differences. 2004;36(3):499-507.

10. Besharat MA. Review of the relationship between attachment styles in couples with marital problems unbeliever.J Psychother 2001;12(5):20.

11. Besharat MA, Iravani M. an investigate the relationship between attachment styles and defense mechanisms. J Psychol 2001;19(3):277-89.

12. Besharat MA, Goli Nezhad M, Ahmedi A. Investigation of the relationship between attachment styles and interpersonal problems. Iran J Psychatry Clin Psycol. 2006;12.

13. Syadpvr Z. Attachment styles and marital satisfaction. Psychol Stud. 2005;1((2,3)):141-59.

14. Makondi B. By comparison, alexithymia male and female students. J Psychol. 2010;7(21):34.

15. Olson DH, Olson AK. Empowering couples: Building on your strengths. Minneapolis, Minnesota.: Life Innovations; 200.

16. Stanley SM, Markman HJ, Whitton SW. Communication, conflict, and commitment: insights on the foundations of relationship success from a national survey. Fam Process. 2002;41(4):659-75.

17. Kathryn DTL. Accomplishing romantic relationship. In: Greene JO, Burleson BR, editors. Handbook of communication and social interaction skills Mahwah. Lawrence Erlbaum Associates; 2005. pp. 685-90.

18. Yum Y, Canary DJ. Maintaining relationships in Korea and the United States: Features of Korean culture that affect relational maintenance beliefs and behaviors.Maintaining relationships through communication. 2003

19. Sanderson CA, Evans SM. Seeing One's Partner Through IntimacyColored Glasses: An Examination of the Processes Underlying the Intimacy Goals-Relationship Satisfaction Link. Pers Soc Psychol Bull. 2001:27(4):463-73.

20. Lippert T, Prager KJ. Daily experiences of intimacy: A study of couples. Pers Relatsh. 2001;8(3):283-98.

21. Cordova JV, Gee CB, Warren LZ. Emotional Skillfulness in Marriage: Intimacy As a Mediator of the Relationship Between Emotional Skillfulness and Marital Satisfaction. J Soc Clin Psychol. 2005;24(2):218-35
22. Weinryb RM, Gustavsson JP, Hellström C, Andersson E, Broberg A, Gunnar R. Interpersonal Problems and personality characteristics: Psychometric studies of the Swedish version of the IIP. Pers Individ Dif. 1996;20(1):13-23.

23. De Rick A, Vanheule S. Alexithymia and DSM-IV personality disorder traits in alcoholic inpatients: A study of the relation between both constructs. Personality and Individual Differences. 2007;43(1):119-29.

24. Carton JS, Kessler EA, Pape CL. Nonverbal decoding skills and relationship well-being in adults. I Nonverbal Behav. 1999;23(1):91-100.

25. Noller P. Misunderstandings in marital communication: A study of couples' nonverbal communication. J Personal Soc Psychol. 1980;39(6):1135.

26. Wachs K, Cordova JV. Mindful relating: exploring mindfulness and emotion repertoires in intimate relationships. J Marital Fam Ther. 2007;33(4):464-81.

27. Montebarocci O, Codispoti M, Baldaro B, Rossi N. Adult attachment style and alexithymia. Pers Individ Dif. 2004;36(3):499-507.

28. Fatehi Zadeh, M., Ahmad, A. Examine the relationship between communication patterns and marital satisfaction working in university. J Fam Res. 2005;2.

29. Fatehi Zadeh M, Ahmadi, A. Effectiveness of interventions based on the theory of Alice's face and online methods of group counseling on marital satisfaction. J Behav Sci. 2008;6.

30. Pouya Manesh J, Ahadi H MMA, Mazaheri M.A, Delavar A. Effectiveness of interventions based on the theory of Alice's face and online methods of group counseling on marital satisfaction. Behavioral Sciences. 1987;6(2):7-22.

31. Haze C, Shaver P. Relationship between attachment styles and marital satisfaction among working women and housewives culture. J Isfahan Med Sch. 2011;29(167):31-46.

32. Farzin rad F, AnfN, Yeke yazdan doost R, Habibi asgar abad A. Relationship between attachment styles and marital satisfaction in couples. J of Behav. 2010;5(12):78-65.

33. Hatfield E, Sprecher S. Measuring passionate love in intimate relationships. J Adolesc .1986;9(4):383-410.

34. Judith A, Feeny JA. Attachment Security and Marital Satisfaction: The Role of Positive Perceptions and Social Support. Pers Soc Psychol Bull. 2001;27(9):1131-43.

35. Banse R. Adult Attachment and Marital Satisfaction: Evidence for Dyadic Configuration Effects. J Soc Pers Relat. 2004;21(2):273-82.

36. Hollist CS, RR. Perceptions of Attachment style and Marital and Quality in Midlife Marriages. Univ Nebraska Lincoln. 2012.

37. Hollist CS, Richard RB. Attachment styles and marital adjustment of social and behavioral science. 2012

38. Ozman O, Atick G. Alexithymia and satisfaction in intimate relationships. Pers Individ Dif. 2009;46(1):43-7.

39. Yelsma P, Marrow S. An Examination of Couples' Difficulties With Emotional Expressiveness and Their Marital Satisfaction. J Fam Commun . 2003;3(1):41-62.

40. Mirgain S, Cordova JV. Emotion Skills and Marital Health: The Association Between Observed and Self-Reported Emotion Skills, Intimacy, and Marital Satisfaction. J Soc Clin Psychol. 2007;26(9):983-1009.

41. LM C. Emotional competence and marital satisfaction. Do elements of emotional competence Relate to Marital satisfaction. 2013.

42. Ellis A. Overcoming resistance: Rational-emotive therapy with difficult clients. Springer; 1985. 